Research article

Open Access

\title{
Early atherosclerosis in systemic sclerosis and its relation to disease or traditional risk factors
}

\author{
Martha E Hettema1', Dan Zhang ${ }^{1}$, Karina de Leeuw ${ }^{1}$, Ymkje Stienstra ${ }^{2}$, Andries J Smit ${ }^{3}$, \\ Cees GM Kallenberg ${ }^{1}$ and Hendrika Bootsma ${ }^{1}$
}

\begin{abstract}
1Department of Internal Medicine, Division of Rheumatology and Clinical Immunology, University Medical Center Groningen, University of Groningen, Hanzeplein 1, PO Box 30.001, 9700 RB Groningen, The Netherlands

2Department of Internal Medicine, University Medical Center Groningen, University of Groningen, Hanzeplein 1, PO Box 30.001, 9700 RB Groningen, The Netherlands

${ }^{3}$ Department of Internal Medicine, Division of Vascular Diseases, University Medical Center Groningen, University of Groningen, Hanzeplein 1, PO Box 30.001, 9700 RB Groningen, The Netherlands
\end{abstract}

Corresponding author: Martha E Hettema, m.e.hettema@int.umcg.nl

Received: 13 Dec 2007 Revisions requested: 15 Jan 2008 Revisions received: 18 Mar 2008 Accepted: 25 Apr 2008 Published: 25 Apr 2008

Arthritis Research \& Therapy 2008, 10:R49 (doi:10.1186/ar2408)

This article is online at: http://arthritis-research.com/content/10/2/R49

(C) 2008 Hettema et al.; licensee BioMed Central Ltd.

This is an open access article distributed under the terms of the Creative Commons Attribution License (http://creativecommons.org/licenses/by/2.0), which permits unrestricted use, distribution, and reproduction in any medium, provided the original work is properly cited.

\begin{abstract}
Introduction Several systemic autoimmune diseases are associated with an increased prevalence of atherosclerosis which could not be explained by traditional risk factors alone. In systemic sclerosis (SSc), microvascular abnormalities are well recognized. Previous studies have suggested an increased prevalence of macrovascular disease as well. We compared patients with SSc to healthy controls for signs of early atherosclerosis by measuring intima-media thickness (IMT) of the common carotid artery in relation to traditional risk factors and markers of endothelial activation.

Methods Forty-nine patients with SSc, of whom $92 \%$ had limited cutaneous SSc, and 32 healthy controls were studied. Common carotid IMT was measured by using B-mode ultrasound. Traditional risk factors for cardiovascular disease were assessed and serum markers for endothelial activation were measured.
\end{abstract}

Results In patients with SSc, the mean IMT (median $0.69 \mathrm{~mm}$, interquartile range [IOR] 0.62 to $0.79 \mathrm{~mm}$ ) was not significantly increased compared with healthy controls $(0.68 \mathrm{~mm}$, IQR 0.56 to $0.75 \mathrm{~mm} ; P=0.067)$. Also, after correction for the confounders age, high-density lipoprotein (HDL) cholesterol, and low-density lipoprotein cholesterol $(P=0.328)$ or using a different model taking into account the confounders age, HDL cholesterol, and history of macrovascular disease $(P=0.474)$, no difference in IMT was present between SSc patients and healthy controls. Plaques were found in three patients and not in healthy controls $(P=0.274)$. In patients, no correlations were found between maximum IMT, disease-related variables, and markers of endothelial activation. Endothelial activation markers were not increased in SSc patients compared with controls.

Conclusion SSc is not associated with an increased prevalence of early signs of atherosclerosis.

\section{Introduction}

Systemic sclerosis (SSc) is a generalized connective tissue disorder characterized by fibrosis of the skin and internal organs and widespread vascular lesions. The pathogenesis of the vasculopathy is not fully understood, but a viral trigger, immune reactions to viral or environmental factors, reperfusion injury, or antiendothelial antibodies may all be involved [1].
Also, angiogenesis is insufficient or defective [2,3]. Most attention has been given to microvascular disease in SSc, but previous studies have suggested an increased prevalence of macrovascular disease as well $[4,5]$.

In other autoimmune diseases, such as systemic lupus erythematosus (SLE), rheumatoid arthritis, and Wegener granulomatosis, a significantly increased prevalence of atherosclerosis has been described [6-10]. Atherosclerosis

$\overline{\mathrm{BMI}}=$ body mass index; $\mathrm{CCA}=$ common carotid artery; $\mathrm{CRP}=\mathrm{C}$-reactive protein; CVD = cardiovascular disease; dcSSc = diffuse cutaneous systemic sclerosis; EScSG = European Scleroderma Study Group; ESR = erythrocyte sedimentation rate; HDL = high-density lipoprotein; ICA = internal carotid artery; IMT = intima-media thickness; IQR = interquartile range; IcSSc = limited cutaneous systemic sclerosis; LDL = low-density lipoprotein; $\mathrm{SLE}=$ systemic lupus erythematosus; $\mathrm{SSc}=$ systemic sclerosis; TM = thrombomodulin; VCAM-1 = vascular cell adhesion molecule-1; vWF = von Willebrand factor. 
nowadays is considered an inflammatory disease in which endothelial cell dysfunction is strongly implicated in its pathogenesis [11], in part related to traditional risk factors like smoking and dyslipidemia. Because of the increased cardiovascular morbidity and mortality in the aforementioned autoimmune diseases, attention has been given to the presence and treatment of cardiovascular risk factors. Despite increased mortality rates in SSc (partly due to cardiac involvement), cardiovascular risk factors and the presence of macrovascular disease have been emphasized less [12,13]. In this study, we assessed signs of early atherosclerosis by measuring intimamedia thickness (IMT) of the common carotid artery (CCA) in patients with SSc and healthy controls. In addition, we related the outcome to traditional risk factors and markers of endothelial activation.

\section{Materials and methods Patients}

Consecutive patients with SSc, according to the American College of Rheumatology criteria [14], attending our outpatient clinic were included. Patients were subclassified in subsets as defined by LeRoy and colleagues $[15,16]$. Forty-nine patients were included. Pregnancy was an exclusion criterion. Healthy subjects were included in this study as controls. Ethical approval for the study was obtained from the Medical Ethical Committee of the University Medical Center Groningen (University of Groningen, Groningen, The Netherlands). Informed consent was obtained from each participant.

Data were obtained from all subjects with respect to traditional risk factors for cardiovascular disease (CVD), including body mass index (BMI), smoking status, diabetes, blood pressure, lipid levels, and family history of CVD (considered positive if first-degree relatives suffered from CVD before 60 years of age).

In patients with SSc, we assessed disease-related factors as possible determinants of macrovascular disease. To assess disease activity, the preliminary European Scleroderma Study Group (EScSG) activity index (a score ranging from 0 to 10) was used. A score higher than 3 denotes active disease $[17,18]$. Also, the revised preliminary SSc severity scale (Medsger severity scale), a measure of activity, damage, and severity, was used. This scale is a nine-organ disease severity scale in which for each organ system a score of 0 to 4 is applied, with 0 being normal and 4 denoting end-stage organ involvement [19]. We also recorded statin use, cumulative prednisolone dose, and current or former use of immunosuppressive agents.

\section{Measurements of intima-media thickness}

B-mode ultrasonography was used to measure the common carotid IMT. Measurements were limited to the CCA and not extended to other segments. The prevalence of increased IMT and/or plaques is substantially higher in the carotid bulb or internal carotid artery (ICA), but the intended quantitative comparison between SSc patients and controls may be hindered by including these segments. An Acuson 128XP ultrasound device with a $7 \mathrm{MHz}$ linear array transducer (Acuson Corporation, now part of Siemens Medical Solutions USA, Inc., Malvern, PA, USA) was used for measuring IMT in all patients and controls, as described before [7,20]. With the subjects in the supine position, the left CCA wall segment was scanned from a lateral transducer position and recorded on s-VHS tape. The CCA wall segment was defined as $1 \mathrm{~cm}$ proximal to the carotid bifurcation. The far wall of the left common artery was assessed at three different positions. Off-line video analysis, using a previously described image analysis program [21], was performed by one reader unaware of patient or control group data or characteristics. The highest IMT value found in this segment was considered to be the maximum IMT, and the mean of three measurements in this segment was considered to be the mean IMT.

\section{Blood analysis}

Lipid levels were measured by routine techniques. Additional serum and plasma samples for determination of markers of endothelial activation were stored at $-20^{\circ} \mathrm{C}$ until analysis. Serum levels of vascular cell adhesion molecule-1 (s-VCAM-1) (R\&D Systems Europe Ltd, Abingdon, UK) and thrombomodulin (TM) (Diaclone, Besançon, France) were measured according to the manufacturers' instructions. Serum was used to determine C-reactive protein (CRP) and plasma was used to determine von Willebrand factor (vWF) using in-house enzyme-linked immunosorbent assays, as described before [7].

\section{Statistical analysis}

Values are expressed as mean \pm standard deviation when variables were normally distributed and as median with interquartile range (IOR) (25th to 75th percentile) in case of a nonnormal distribution. Because the number of patients with diffuse cutaneous SSc (dSSc) was low in our patient group, subset analysis could not be performed. Differences between patients and controls were assessed by Student $t$ test, MannWhitney $U$ test, and $\chi^{2}$ test (Pearson chi-square or Fisher exact test) as appropriate. Linear regression was used to assess the relationship between IMT and the different groups (SSc patients and healthy controls). An unadjusted analysis in which no corrections were made for possible confounders and an adjusted analysis in which corrections were made for possible confounders are presented. The variables were entered manually. The level of significance for the association between group and outcome variable was set at a $P$ value of less than 0.05 . The variables age, gender, BMI, and smoking were also studied as potential effect modifiers in the relationship of interest. The correlation between maximum IMT and diseaserelated factors and endothelial markers was assessed by Spearman rank correlation coefficient since maximum IMT was non-normally distributed. All analyses were carried out with the 
Statistical Package of Social Science, version 12.1. for Windows (SPSS Inc., Chicago, IL, USA).

\section{Results}

\section{Characteristics of patients and controls}

The demographic characteristics and the traditional risk factors of SSc patients and healthy controls are shown in Table 1. Patients tended to be older $(55.4 \pm 11.6$ versus $50.9 \pm$ 10.1 years; $P=0.078$ ) and used significantly more statins (14\% versus $0 \% ; P=0.038$ ) than healthy controls. Patients had lower levels of high-density lipoprotein (HDL) cholesterol ( $1.40 \mathrm{mmol} / \mathrm{L}$, IQR 1.23 to $1.80 \mathrm{mmol} / \mathrm{L}$, versus $1.68 \mathrm{mmol} / \mathrm{L}$, IQR 1.48 to $1.89 \mathrm{mmol} / \mathrm{L} ; P=0.027)$ and higher levels of triglycerides ( $1.36 \mathrm{mmol} / \mathrm{L}$, IQR 1.16 to $2.14 \mathrm{mmol} / \mathrm{L}$, versus 1.17 $\mathrm{mmol} / \mathrm{L}$, IQR 0.77 to $1.67 \mathrm{mmol} / \mathrm{L} ; P=0.030$ ) than controls. No significant differences were found in other cardiovascular risk factors. Four patients had a history of macrovascular events compared with none in the control group.

Patients with SSc had a median disease duration of 6 years and had experienced Raynaud phenomenon for almost 11 years. Limited cutaneous SSc (IcSSc) was present in 92\% of patients and diffuse cutaneous SSc was present in $8 \%$ of patients. Patients had a median modified Rodnan skin score of 7.0 (IOR 4.5 to 14.0 ), a preliminary EScSG disease activity index of 0.5 (IQR 0.5 to 1.75 ), and a revised preliminary SSc severity scale score (Medsger severity scale score) of 6.0 (IOR 4.5 to 7.0). The preliminary EScSG disease activity index

Table 1

\section{Traditional risk factors in systemic sclerosis patients and healthy controls}

\begin{tabular}{|c|c|c|c|}
\hline Characteristic & Patients $(n=49)$ & Controls $(n=32)$ & $P$ value \\
\hline Age, years & $55.4 \pm 11.6$ & $50.9 \pm 10.1$ & 0.078 \\
\hline Male gender, number (percentage) & $8(16 \%)$ & $3(9.4 \%)$ & 0.513 \\
\hline Body mass index, $\mathrm{kg} / \mathrm{m}^{2}$ & $23.7 \pm 2.9$ & $24.0 \pm 2.9$ & 0.582 \\
\hline \multicolumn{4}{|l|}{ Smoking } \\
\hline Pack years for smokers, number (percentage) & $3(6 \%)$ & $2(6.5 \%)$ & 1.000 \\
\hline Median (range) & $20(1-48)$ & $10(6-14)$ & \\
\hline Diabetes mellitus, number (percentage) & $2(4 \%)$ & 0 & 0.523 \\
\hline Hypertension treated with antihypertensive agents, number (percentage) & $12(24 \%)$ & $2(6 \%)$ & 0.120 \\
\hline \multicolumn{4}{|l|}{ Blood pressure, $\mathrm{mm} \mathrm{Hg}$} \\
\hline Systolic & $120(110-135)$ & $120(110-125)$ & 0.409 \\
\hline Diastolic & $75(70-80)$ & $75(70-80)$ & 0.379 \\
\hline \multicolumn{4}{|l|}{ Cholesterol, $\mathrm{mmol} / \mathrm{L}$} \\
\hline Total & $5.22 \pm 1.00$ & $5.53 \pm 1.06$ & 0.217 \\
\hline Low-density lipoprotein & $3.02 \pm 0.85$ & $3.06 \pm 1.08$ & 0.871 \\
\hline High-density lipoprotein & $1.40(1.23-1.80)$ & $1.68(1.48-1.89)$ & 0.027 \\
\hline Triglycerides, $\mathrm{mmol} / \mathrm{L}$ & $1.36(1.16-2.14)$ & $1.17(0.77-1.67)$ & 0.030 \\
\hline Lipid-lowering drugs, number (percentage) & $7(14 \%)$ & 0 & 0.038 \\
\hline Simvastatin, number (mean dose in milligrams) & $4(20)$ & 0 & \\
\hline Atorvastatin, number (mean dose in milligrams) & $2(25)$ & 0 & \\
\hline Rosuvastatin, number (mean dose in milligrams) & $1(10)$ & 0 & \\
\hline Family history of cardiovascular disease, number (percentage) & $10(20 \%)$ & $5(16 \%)$ & 0.603 \\
\hline Cardiovascular history, number (percentage) & $4(8 \%)$ & 0 & 0.149 \\
\hline Cardiovascular & 1 & & \\
\hline Cerebrovascular & 1 & & \\
\hline Peripheral vascular disease & 2 & & \\
\hline C-reactive protein, $\mathrm{mg} / \mathrm{L}$ & $3.5(1.6-7.0)$ & $0.8(0.3-2.0)$ & $<0.001$ \\
\hline
\end{tabular}


may have been an underestimation of reality since not all variables (especially erythrocyte sedimentation rate [ESR] and complement) were available. As shown in Table 1, CRP levels were not substantially elevated, suggesting normal ESR levels. However, patients had significantly higher CRP levels than controls (3.5, IQR 1.6 to 7.0, versus 0.8, IQR 0.3 to 2.0 ; $P<$ $0.001)$. Forty-three percent of patients were current or former users of prednisolone, with a median cumulative dose of $3.6 \mathrm{~g}$ (1.9 to $16.1 \mathrm{~g}$ ) (Table 2 ).

\section{Intima-media thickness}

The median values for the mean IMT measurements in the CCA were $0.69 \mathrm{~mm}$ (IOR 0.62 to $0.79 \mathrm{~mm}$ ) in patients and $0.68 \mathrm{~mm}$ (IQR 0.56 to $0.75 \mathrm{~mm}$ ) in controls (Figure 1a). Also, IMT values were comparable between SSc patients and controls for each age decade. Among the four outliers in the group of SSc patients with an IMT of greater than $1.10 \mathrm{~mm}$, one patient had a history of a cerebrovascular accident and one patient was known to have left ventricular dysfunction probably caused by coronary artery disease. Both had other cardiovascular risk factors like current or former smoking and hypertension. The other two patients were not known to have clinically manifest CVDs. One of these patients had a family history of CVD. Other risk factors were not present. Although plaques were not a primary endpoint, they were observed in three patients and not in healthy controls. Linear regression analysis of the mean IMT in the CCA between controls and patients, when not corrected for possible confounders, demonstrated no significant difference in mean IMT $(B=0.101 ; P$ $=0.067$ ) (Table 3). Also, no significant differences were seen between the groups after correction for the strongest confounders. Both in the model with the confounders age, HDL cholesterol, and low-density lipoprotein (LDL) cholesterol $(B=$ $0.042 ; P=0.328$ ) and in the model with the confounders age, $\mathrm{HDL}$ cholesterol, and history of macrovascular disease $(\mathrm{B}=$ 0.030; $P=0.474$ ), no differences were found between patients and healthy controls. The possible relationship between mean IMT and SSc patients versus controls was lost when traditional risk factors were entered into the regression analysis. The addition of the confounder history of hypertension did not change the outcome. No correction for systolic and diastolic blood pressure, use of statins, smoking, diabetes mellitus, gender, BMI, total cholesterol, or triglycerides was necessary since these outcome parameters were not confounders in the linear regression model. No effect modification by age, gender, BMI, or smoking was found.

No significant differences were seen for the maximum IMT of the CCA between SSc patients $(0.83 \mathrm{~mm}$, IQR 0.70 to 0.97 $\mathrm{mm}$ ) and healthy controls $(0.77 \mathrm{~mm}$, IQR 0.70 to $0.88 \mathrm{~mm}$ ) by means of linear regression analysis before or after correction for the confounders age, HDL cholesterol, gender, and history of macrovascular disease (Figure $1 \mathrm{~b}$ and Table 4). The addition of the other confounders (that is, history of hypertension, diastolic blood pressure, and LDL cholesterol) did not change
Table 2

Characteristics of patients with systemic sclerosis

\begin{tabular}{|c|c|}
\hline Disease characteristic & $N=49$ \\
\hline \multicolumn{2}{|c|}{ Systemic sclerosis subset, number (percentage) } \\
\hline Diffuse cutaneous systemic sclerosis & $4(8 \%)$ \\
\hline Limited cutaneous systemic sclerosis & $45(92 \%)$ \\
\hline Disease duration, years & $6(2-12)$ \\
\hline Raynaud phenomenon duration, years & $11(6-25)$ \\
\hline \multicolumn{2}{|l|}{ Antibody, number (percentage) } \\
\hline Scl70 (topoisomerase 1) & $4(8 \%)$ \\
\hline Centromere & $22(45 \%)$ \\
\hline Nuclear ribonucleoprotein & $2(4 \%)$ \\
\hline Antinuclear antibodies, not specified & $17(35 \%)$ \\
\hline None & $4(8 \%)$ \\
\hline EScSG disease activity index & $0.5(0.5-1.5)$ \\
\hline Medsger severity scale score & $6.0(4.5-7.0)$ \\
\hline Modified Rodnan skin score & $7.0(4.5-14.0)$ \\
\hline \multicolumn{2}{|l|}{ Prednisolone use, number (percentage) } \\
\hline None & $28(57 \%)$ \\
\hline Former & $13(27 \%)$ \\
\hline Current & $8(16 \%)$ \\
\hline Cumulative prednisolone dose, grams & $3.6(1.9-16.1)$ \\
\hline \multicolumn{2}{|c|}{ Immunosuppressive agents, number (percentage) } \\
\hline Never used & $25(51 \%)$ \\
\hline Former or current users & $24(49 \%)$ \\
\hline \multicolumn{2}{|l|}{ Methotrexate } \\
\hline Current & 12 \\
\hline Former & 7 \\
\hline \multicolumn{2}{|l|}{ Cyclophosphamide } \\
\hline Current & 2 \\
\hline Former & 4 \\
\hline \multicolumn{2}{|l|}{ Azathioprine } \\
\hline Current & 3 \\
\hline Former & 3 \\
\hline \multicolumn{2}{|l|}{ Cyclosporin } \\
\hline Current & 0 \\
\hline Former & 1 \\
\hline
\end{tabular}

Unless stated otherwise, data are expressed as mean \pm standard deviation when normally distributed and as median (interquartile range) when non-normally distributed. EScSG, European Scleroderma Study Group. 
Table 3

Linear regression analysis for risk factors for mean intima-media thickness of the left common carotid artery in systemic sclerosis patients and healthy controls

\begin{tabular}{lccc}
\hline Group (controls, patients) & $\mathrm{B}^{\mathrm{a}}$ & $95 \%$ confidence interval & $P$ value \\
\hline Unadjusted/crude & 0.101 & $-0.007,0.209$ & 0.067 \\
Adjusted & 0.042 & $-0.043,0.128$ & 0.328 \\
Adjustedc & 0.030 & $-0.054,0.114$ & 0.474 \\
\hline
\end{tabular}

aB is the regression coefficient. In the adjusted models, corrections were made for the confounders bage, high-density lipoprotein (HDL) cholesterol, and low-density lipoprotein cholesterol or cage, HDL cholesterol, and history of macrovascular disease; a total of 66 patients and controls were available for this analysis.

the outcome. In patients, no correlations were found between maximum IMT, CRP, and disease-related variables.

\section{Endothelial activation markers}

Markers of endothelial activation were not increased in patients with SSc. Compared with controls, levels of VCAM-1 were even decreased $(229 \mathrm{ng} / \mathrm{mL}$, IQR 188 to $311 \mathrm{ng} / \mathrm{mL}$, versus $287 \mathrm{ng} / \mathrm{mL}$, IQR 236 to $350 \mathrm{ng} / \mathrm{mL} ; P=0.014$ ). No differences between SSc patients and controls were found in levels of vWF (72\%, IOR $34 \%$ to $125 \%$, versus $71 \%$, IQR $48 \%$ to $110 \% ; P=0.691)$ and TM (3.8 ng/mL, IOR 2.3 to 5.0 $\mathrm{ng} / \mathrm{mL}$, versus $2.9 \mathrm{ng} / \mathrm{mL}$, IQR 2.1 to $3.7 \mathrm{ng} / \mathrm{mL} ; P=0.151$ ) (Figure 2). Levels of endothelial markers were not correlated with maximum IMT.

\section{Discussion}

This study did not show differences in the IMT of the CCA and prevalence of plaques between patients with SSc and healthy controls, suggesting no increased prevalence of early atherosclerotic macrovascular disease in SSc. Also, no correlations were found between IMT, disease-related factors, and markers of endothelial activation. Traditional risk factors, like increasing age and dyslipidemia, accounted for increased IMT values in SSc patients and controls.
After the first reports suggesting an increased prevalence of macrovascular involvement in SSc, several studies have been performed in the last decade using IMT of the carotid artery as a marker of early atherosclerosis. Lekakis and colleagues [22], Kaloudi and colleagues [23], and Bartoli and colleagues $[24,25]$ found strongly increased IMT values in the CCA in SSc patients compared with controls. In these studies, mean IMT values were markedly higher than in our patients whereas mean age was comparable. It is not known whether patient groups in studies by Kaloudi and colleagues [23] and Bartoli and colleagues [24,25] are from overlapping cohorts since these studies were performed in the same center and published in the same period. A larger percentage of diffuse cutaneous systemic sclerosis (dcSSc) subtype was present in these studies compared with our study, although Kaloudi and colleagues [23] found no significant differences between mean IMT between subtypes. On the other hand, our results are in agreement with those of Cheng and colleagues [26,27] and Szucs and colleagues [28], who found no differences in IMT values in SSc patients compared with controls. Apart from a younger age and a larger percentage of dcSSc subtype in the study by Cheng and colleagues [27], age was comparable, as were IMT values. No difference was present in IMT values between subsets in this study either [26]. In view of this

Figure 1

(a)

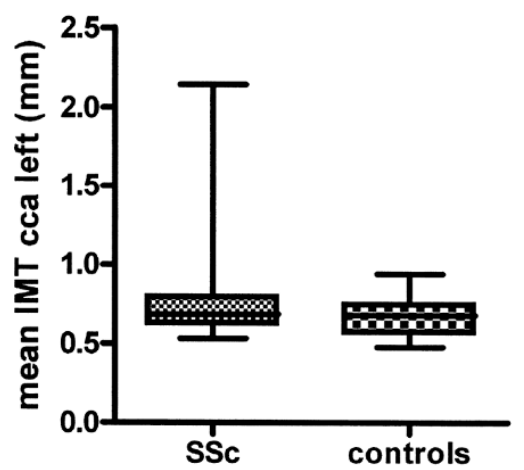

(b)

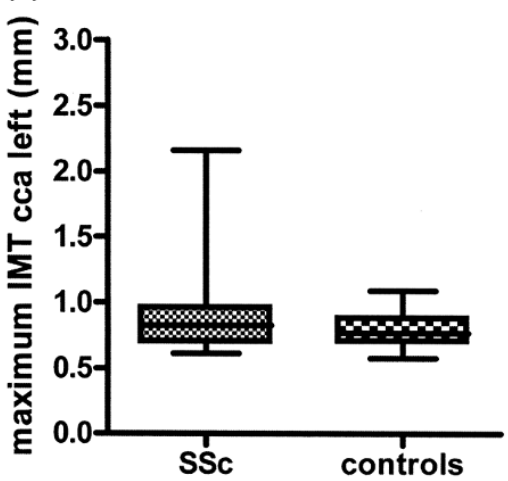

Box plots of (a) mean and (b) maximum left common carotid artery (CCA) intima-media thickness (IMT) of systemic sclerosis (SSc) patients and healthy controls. Data are uncorrected for confounders. The median, interquartile range, and minimum and maximum values are shown. 
Table 4

Linear regression analysis unadjusted and adjusted for risk factors for maximum intima-media thickness of the left common carotid artery in systemic sclerosis patients and healthy controls

\begin{tabular}{lccc}
\hline Group (controls, patients) & $\mathrm{B}^{\mathrm{a}}$ & 95\% confidence interval & $P$ value \\
\hline Unadjusted/crude & 0.101 & $-0.017,0.219$ & 0.093 \\
Adjusted $^{b}$ & 0.028 & $-0.071,0.127$ & 0.577 \\
Adjustedc $^{c}$ & 0.022 & $-0.081,0.126$ & 0.668
\end{tabular}

aB is the regression coefficient. In the adjusted models, corrections were made for the confounders bage, high-density lipoprotein (HDL) cholesterol, and gender or cage, HDL cholesterol, and history of macrovascular disease; a total of 66 patients and controls were available for this analysis.

findings and given the small number of patients with dcSSc in our study, we did not perform a subset analysis. Overall, these discrepancies between studies in the presence of early atherosclerosis as measured by common carotid IMT in SSc patients might be explained by methodological differences, such as patients included in the study and comorbidity.

In our SSc patients, lipid levels and statin use were statistically different from healthy controls. After correction for the strongest confounders in our model, no differences were seen in IMT values between SSc patients and healthy controls. Although statin use was no confounder in our model, a meta-analysis showed that statin therapy is efficient in decreasing the rate of carotid atherosclerosis progression in the long term [29]. Otherwise, statins may have a potential benefit in preventing endothelial dysfunction in SSc patients [30].

Treatment with immunosuppressive agents, especially corticosteroids, influences the atherogenic process. Corticosteroids are considered to have atherogenic properties [31], like azathioprine [32], whereas for hydroxychloroquine [31] and methotrexate [9], a protective effect against atherosclerosis has been described. Otherwise, immunosuppressive therapy with prednisolone, cyclophosphamide, or hydroxychloquine

Figure 2

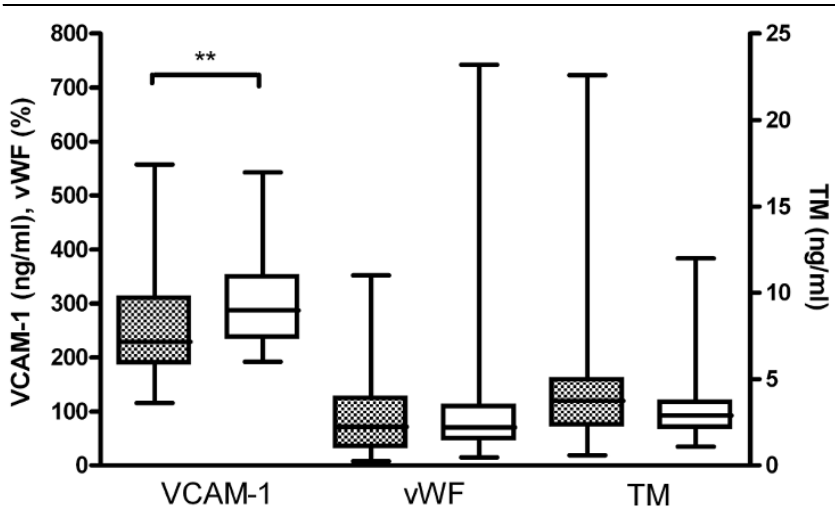

Endothelial activation markers. Boxes indicate the median value and the interquartile ranges. Lines indicate the minimum and maximum values. Dotted bars represent systemic sclerosis patients and open bars represent controls. TM, thrombomodulin; VCAM-1, vascular cell adhesion molecule-1; vWF, von Willebrand factor. ${ }^{\star \star} P<0.05$. was associated with the absence of plaques in patients with SLE [33]. It is difficult to establish whether the observed associations between immunosuppressive agents and atherosclerosis are due to the immunosuppressive agents themselves or to their effect on the activity of the autoimmune disease. In our study, $49 \%$ were former or current users of immunosuppressive agents. No association was found between maximum IMT and cumulative prednisolone dose and use of other immunosuppressive agents.

Markers of inflammation, such as CRP, are related to the risk of cardiovascular and peripheral vascular disease. Increased levels of CRP are associated with increased risk of symptomatic disease [34,35]. In our population, CRP levels were significantly elevated compared with healthy controls. The CRP levels we found might have been associated with future coronary events $[34,35]$, but we found no association between CRP and IMT values. This can be explained by the study design. Our study was not designed to find a relationship between CRP and risk of CVD, and we did not exclude other conditions that could explain elevated CRP levels, like intercurrent infections. Otherwise, in SSc patients, besides elevations due to infection, no significant elevations of CRP levels are seen [36].

Surprisingly, we did not find elevated levels of endothelial activation markers. Our population of SSc patients was heterogeneous with respect to disease duration. The typical patient had inactive disease. Most inflammation is expected in the early stages of the disease or in patients with active disease. Also, by using the Medsger severity scale, we could not find an association between macrovascular disease and the severity of SSc. This might explain the absence of increased levels of endothelial activation markers. All these data point to the absence of premature atherosclerosis in SSc.

Our results might be an underestimation of atherosclerosis in SSc patients and controls. Besides the possible explanations as stated above, our patients were suffering predominantly from lcSSc, in which inflammation is not always present [37]. However, when IMT values were analyzed in subsets, other authors did not find differences in these values between subsets $[23,26]$. Furthermore, we used IMT values of the CCA. 
This segment is commonly evaluated in our laboratory as it can be approached easily and measurements on this segment are reproducible. Using the same protocol as described here, we found increased IMT values in patients with SLE [38]. However, atherosclerotic lesions appear later in the CCA than in the ICA or bulb, but these latter two segments are more difficult to visualize [39]. Also, it can be difficult to assess whether IMT of the CCA represents atherosclerosis or vascular hypertrophy [40]. Although other noninvasive markers of early changes in the arterial wall are available (such as arterial wall thickening and stiffening), carotid IMT has been used more frequently and has been found to be a strong predictor of future vascular events $[40,41]$.

\section{Conclusion}

IMT of the CCA is not increased in patients with SSc compared with controls, either when uncorrected or corrected for traditional risk factors. So, SSc seems not to be associated with increased early atherosclerotic macrovascular disease. It seems that, although SSc is characterized by endothelial dysfunction, this is reflected mainly in microvascular disease.

\section{Competing interests}

The authors declare that they have no competing interests.

\section{Authors' contributions}

MEH participated in the conception and design of the study, participated in the recruitment of patients and controls and data collection, helped to conduct the statistical analysis, and was involved in drafting the manuscript or revising it critically. $\mathrm{KdL}$ participated in the conception and design of the study, participated in the recruitment of patients and controls and data collection, helped to perform enzyme-linked immunosorbent assay (ELISA) experiments, and was involved in drafting the manuscript or revising it critically. AJS, CGMK, and HB participated in the conception and design of the study and were involved in drafting the manuscript or revising it critically. DZ participated in the recruitment of patients and controls and data collection and helped to perform ELISA experiments. YS helped to conduct the statistical analysis. All authors read and approved the final manuscript.

\section{References}

1. Kahaleh MB, LeRoy EC: Autoimmunity and vascular involvement in systemic sclerosis (SSc). Autoimmunity 1999, 31:195-214.

2. LeRoy EC: Systemic sclerosis. A vascular perspective. Rheum Dis Clin North Am 1996, 22:675-694.

3. Mackiewicz Z, Sukura A, Povilenaité D, Ceponis A, Virtanen I, Hukkanen M, Konttinen YT: Increased but imbalanced expression of VEGF and its receptors has no positive effect on angiogenesis in systemic sclerosis skin. Clin Exp Rheumatol 2002, 20:641-646.

4. Ho ML, Veale D, Eastmond C, Nuki G, Belch J: Macrovascular disease and systemic sclerosis. Ann Rheum Dis 2000, 59:39-43.

5. Veale DJ, Collidge TA, Belch JJF: Increased prevalence of symptomatic macrovascular disease in systemic-sclerosis. Ann Rheum Dis 1995, 54:853-855.
6. Alkaabi JK, Ho M, Levison R, Pullar T, Belch JJF: Rheumatoid arthritis and macrovascular disease. Rheumatology 2003, 42:292-297.

7. De Leeuw K, Sanders JS, Stegeman C, Smit A, Kallenberg CG, Bijl $\mathrm{M}$ : Accelerated atherosclerosis in patients with Wegener's granulomatosis. Ann Rheum Dis 2005, 64:753-759.

8. Esdaile JM, Abrahamowicz M, Grodzicky T, Li Y, Panaritis C, du Berger R, Côte R, Grover SA, Fortin PR, Clarke AE, Senécal JL: Traditional Framingham risk factors fail to fully account for accelerated atherosclerosis in systemic lupus erythematosus. Arthritis Rheum 2001, 44:2331-2337.

9. Wallberg-Jonsson S, Ohman M, Rantapaa-Dahlqvist S: Which factors are related to the presence of atherosclerosis in rheumatoid arthritis? Scand J Rheumatol 2004, 33:373-379.

10. Shoenfeld Y, Gerli R, Doria A, Matsuura E, Cerinic MM, Ronda N, Jara LJ, Abu-Shakra M, Meroni PL, Sherer Y: Accelerated atherosclerosis in autoimmune rheumatic diseases. Circulation 2005, 112:3337-3347.

11. Ross R: Atherosclerosis - An inflammatory disease. $N$ Engl J Med 1999, 340:115-126.

12. Mayes MD, Lacey JV Jr, Beebe-Dimmer J, Gillespie BW, Cooper $B$, Laing TJ, Schottenfeld D: Prevalence, incidence, survival, and disease characteristics of systemic sclerosis in a large US population. Arthritis Rheum 2003, 48:2246-2255.

13. loannidis JP, Vlachoyiannopoulos PG, Haidich AB, Medsger TA Jr, Lucas M, Michet CJ, Kuwana M, Yasuoka H, Hoogen F van den, Te Boome L, van Laar JM, Verbeet NL, Matucci-Cerinic M, Georgountzos A, Moutsopoulos HM: Mortality in systemic sclerosis: an international meta-analysis of individual patient data. $\mathrm{Am} J$ Med 2005, 118:2-10.

14. Subcommittee for Scleroderma Criteria of the American Rheumatism Association Diagnostic and Therapeutic Criteria Committee: Preliminary criteria for the classification of systemic-sclerosis (scleroderma). Arthritis Rheum 1980, 23:581-590.

15. LeRoy EC, Black C, Fleischmajer R, Jablonska S, Krieg T, Medsger TA Jr, Rowell N, Wollheim F: Scleroderma (systemic-sclerosis) - classification, subsets and pathogenesis. J Rheumatol 1988, 15:202-205

16. LeRoy EC, Medsger TA Jr: Criteria for the classification of early systemic sclerosis. J Rheumato/ 2001, 28:1573-1576.

17. Valentini G, Della Rossa A, Bombardieri S, Bencivelli W, Silman AJ, D'Angelo S, Cerinic MM, Belch JF, Black CM, Bruhlmann P, Czirják L, De Luca A, Drosos AA, Ferri C, Gabrielli A, Giacomelli R, Hayem G, Inanc M, McHugh NJ, Nielsen H, Rosada M, Scorza R, Stork J, Sysa A, Hoogen FH van den, Vlachoyiannopoulos PJ: European multicentre study to define disease activity criteria for systemic sclerosis. II. Identification of disease activity variables and development of preliminary activity indexes. Ann Rheum Dis 2001, 60:592-598.

18. Valentini G, Bencivelli W, Bombardieri S, D'Angelo S, Della Rossa A, Silman AJ, Black CM, Czirjak L, Nielsen H, Vlachoyiannopoulos PG: European Scleroderma Study Group to define disease activity criteria for systemic sclerosis. III. Assessment of the construct validity of the preliminary activity criteria. Ann Rheum Dis 2003, 62:901-903.

19. Medsger TA, Bombardieri S, Czirjak L, Scorza R, Della Rossa A, Bencivelli W: Assessment of disease severity and prognosis. Clin Exp Rheumatol 2003, 21:S42-S46.

20. Blaauw J, van Pampus MG, van Doormaal JJ, Fokkema MR, Fidler V, Smit AJ, Aarnoudse JG: Increased intima-media thickness after early-onset preeclampsia. Obstet Gynecol 2006, 107:1345-1351.

21. Selzer RH, Hodis HN, Kwong-Fu H, Mack WJ, Lee PL, Liu CR, Liu $\mathrm{CH}$ : Evaluation of computerized edge tracking for quantifying intima-media thickness of the common carotid artery from Bmode ultrasound images. Atherosclerosis 1994, 111:1-11.

22. Lekakis J, Mavrikakis M, Papamichael C, Papazoglou S, Economou O, Scotiniotis I, Stamatelopoulos K, Vemmos C, Stamatelopoulos S, Moulopoulos S: Short-term estrogen administration improves abnormal endothelial function in women with systemic sclerosis and Raynaud's phenomenon. Am Heart J 1998, 136:905-912.

23. Kaloudi O, Basta G, Perfetto F, Bartoli F, Del Rosso A, Miniati I, Conforti ML, Generini S, Guiducci S, Abbate R, Pignone A, Castellani S, Livi R, De Caterina R, Matucci-Cerinic M: Circulating levels of Nepsilon-(carboxymethyl)lysine are increased in systemic sclerosis. Rheumatology (Oxford) 2007, 46:412-416. 
24. Bartoli F, Angotti C, Fatini C, Conforti ML, Guiducci S, Blagojevic J, Melchiorre D, Fiori G, Generini S, Damjanov N, Rednic S, Pignone A, Castellani S, Abbate R, Matucci Cerinic M: Angiotensin-converting enzyme I/D polymorphism and macrovascular disease in systemic sclerosis. Rheumatology (Oxford) 2007, 46:772-775.

25. Bartoli F, Blagojevic J, Bacci M, Fiori G, Tempestini A, Conforti ML Guiducci S, Miniati I, Di Chicco M, Del Rosso A, Perfetto F, Castellani S, Pignone A, Cerinic MM: Flow-mediated vasodilation and carotid intima-media thickness in systemic sclerosis. Ann NY Acad Sci 2007, 1108:283-290.

26. Cheng KS, Tiwari A, Boutin A, Denton CP, Black CM, Morris R, Hamilton G, Seifalian AM: Carotid and femoral arterial wall mechanics in scleroderma. Rheumatology (Oxford) 2003, 42:1299-1305.

27. Cheng KS, Tiwari A, Boutin A, Denton CP, Black CM, Morris R, Seifalian AM, Hamilton G: Differentiation of primary and secondary Raynaud's disease by carotid arterial stiffness. Eur J Vasc Endovasc Surg 2003, 25:336-341.

28. Szucs G, Tímár O, Szekanecz Z, Dér H, Kerekes G, Szamosi S, Shoenfeld Y, Szegedi G, Soltész P: Endothelial dysfunction precedes atherosclerosis in systemic sclerosis. Relevance for prevention of vascular complications. Rheumatology (Oxford) 2007, 46:759-762

29. Kang S, Wu Y, Li X: Effects of statin therapy on the progression of carotid atherosclerosis: a systematic review and meta-analysis. Atherosclerosis 2004, 177:433-442.

30. Kuwana M: Potential benefit of statins for vascular disease in systemic sclerosis. Curr Opin Rheumato/ 2006, 18:594-600.

31. Petri M, Lakatta C, Magder L, Goldman D: Effect of prednisone and hydroxychloroquine on coronary artery disease risk factors in systemic lupus erythematosus: a longitudinal data analysis. Am J Med 1994, 96:254-259.

32. Doria A, Shoenfeld Y, Wu R, Gambari PF, Puato M, Ghirardello A, Gilburd B, Corbanese S, Patnaik M, Zampieri S, Peter JB, Favaretto E, laccarino L, Sherer Y, Todesco S, Pauletto P: Risk factors for subclinical atherosclerosis in a prospective cohort of patients with systemic lupus erythematosus. Ann Rheum Dis 2003, 62:1071-1077.

33. Roman MJ, Shanker B, Davis A, Lockshin MD, Sammaritano L, Simantov R, Crow MK, Schwartz JE, Paget SA, Devereux RB, Salmon JE: Prevalence and correlates of accelerated atherosclerosis in systemic lupus erythematosus. $N$ Engl J Med 2003, 349:2399-2406.

34. Folsom AR, Aleksic N, Catellier D, Juneja HS, Wu KK: C-reactive protein and incident coronary heart disease in the Atherosclerosis Risk In Communities (ARIC) study. Am Heart J 2002, 144:233-238.

35. Ridker PM, Cushman M, Stampfer MJ, Tracy RP, Hennekens CH: Plasma concentration of C-reactive protein and risk of developing peripheral vascular disease. Circulation 1998, 97:425-428.

36. Kucharz EJ, Grucka-Mamczar E, Mamczar A, Brzezinska-Wcislo L: Acute-phase proteins in patients with systemic sclerosis. Clin Rheumatol 2000, 19:165-166.

37. Valentini G, Silman AJ, Veale D: Assessment of disease activity. Clin Exp Rheumatol 2003, 21:S39-S41.

38. De Leeuw K, Freire B, Smit AJ, Bootsma H, Kallenberg CG, Bijl M: Traditional and non-traditional risk factors contribute to the development of accelerated atherosclerosis in patients with systemic lupus erythematosus. Lupus 2006, 15:675-682.

39. Poredos P: Intima-media thickness: indicator of cardiovascular risk and measure of the extent of atherosclerosis. Vasc Med 2004, 9:46-54.

40. Simon A, Gariepy J, Chironi G, Megnien JL, Levenson J: Intimamedia thickness: a new tool for diagnosis and treatment of cardiovascular risk. J Hypertens 2002, 20:159-169.

41. Lorenz MW, Markus HS, Bots ML, Rosvall M, Sitzer M: Prediction of clinical cardiovascular events with carotid intima-media thickness: a systematic review and meta-analysis. Circulation 2007, 115:459-467. 